\title{
Information processing of letter and word pairs as a function of on and off times'
}

\author{
M. GREENBERG, M. S. HELFER, AND M. S. MAYZNER² \\ NEW YORK UNIVERSITY
}

\begin{abstract}
The present study seeks to extend a provisional model of visual information processing with sequential inputs currently under development, employing a computer-based cathode-ray tube display system. Letter and word pairs were presented for 28 different on-off time combinations with on times ranging from 5 msec to $50 \mathrm{msec}$ and off times ranging from $1 \mathrm{msec}$ to $125 \mathrm{msec}$. The results suggest that both on, off, and total processing times affect per cent correct detections, and that while a gradual increase in per cent correct detections occurs up to about 50 msec of total processing time, a marked discontinuity appears to occur approximately between 50 and $60 \mathrm{msec}$ of total processing time, with per cent correct detections jumping abruptly from about $40 \%$ correct detections to about $90 \%$ correct detections over a total processing time span of only $10 \mathrm{msec}$.
\end{abstract}

The information processing time associated with letter pairs presented sequentially in a tachistoscope was examined recently by Schiller (1966) in an experimental paradigm that studied forward and backward masking as a function of the relative overlap of the test and the masking stimuli, the relative intensity of the masking stimulus, and the length of the time interval between the stimuli. All three parameters were shown to have systematic effects on the phenomena in question, with masking increasing with increasing spatial overlap between stimuli and with increasing intensity of the masking stimulus, while decreasing with increasing time between test and masking stimuli.

More recently Mayzner, Tresselt, and Helfer (1967b) have proposed a provisional model of visual information processing with sequential inputs, which has implications for the type of experimental paradigm employed by Schiller (1966). Very briefly our provisional model has suggested that when visual inputs (whose on time varies from $50 \mu \mathrm{sec}$ to approximately $50 \mathrm{msec}$ and also are clearly above threshold) enter the visual system, they pass through a succession of information or data processing components, i.e., visual receptor mechanisms, visual cortex, higher centers (central storage), a gating mechanism, and finally arrive, after approximately $130 \mathrm{msec}$ of real-time input processing, at a component we have called "subjective visual experience" (SVE), which represents the S's actual subjective visual experience associated with any given visual input which is. above threshold and which lasts from $50 \mu \mathrm{sec}$ to approximately $50 \mathrm{msec}$. Further, we have estimated input processing time in SVE to be on the order of approximately $100 \mathrm{msec}$.

In the present study we shall be concerned with presenting two inputs sequentially, as Schiller (1966) did, but, in addition, varying (1) the content of these two inputs, e.g., letter pairs, word pairs, and random letter string pairs, and (2) the on time as well as the off time of the two inputs. Thus, this study represents, in part, an extension of Schiller's (1966) work and also has implications for our provisional model of visual information processing with sequential inputs, particularly in reference to the SVE component of the model.

\section{Subjects}

\section{METHOD}

The Ss were two volunteers, R.H. and P.K., with equal visual acuity for both eyes. R.H. was male and P.K. was female.

\section{Apparatus}

The stimuli were presented on two Fairchild cathode-ray tube (CRT) display consoles (Type 737A, manufactured by the Fairchild Camera and Instrument Corp.) simultaneously, permitting the two Ss to be tested at the same time, but with the CRT consoles separated sufficiently in space so as to avoid any $S$ interference. The two Fairchild CRTs were slaved to a 340 Master Display coupled to a PDP-7 digital computer (Master Display and computer manufactured by the Digital Equipment Corp.), which generated the stimulus sequences automatically, once the appropriate display tapes had been entered into the PDP-7's core memory. A complete description of this computer-based CRT display system and the associated display programs may be found in Mayzner (1968) and Mayzner, Tresselt, and Helfer (1967a). Precise timing of the displays was assured by the $20,000 \mathrm{~Hz}$ crystal clock in the computer and the P24 phosphor of the Fairchild displays, whose decay time is on the order of a few microseconds. Display luminance was approximately $1 \mathrm{~mL}$ for a steady-state display, as measured with a Macbeth illuminometer. $\mathbf{S}$ was positioned $2 \mathrm{ft}$ in front of the display, with letter size $1 / 2 \mathrm{in}$. high and $3 / 8$ in. wide.

\section{Materials}

The stimulus pairs involved five different experimental test conditions, labeled A, B, C, D, and E. For Condition A, a single letter was followed by another single letter. For Condition B, three randomly chosen adjacent letters were followed by another set of three randomly chosen adjacent letters. For Condition C, five randomly chosen adjacent letters were followed by another set of five randomly chosen adjacent letters. For Condition D, a three-letter word was followed by another three-letter word. For Condition E, a five-letter word was followed by another five-letter word. In all five conditions, the second input occupied the same spatial location as the first input, thus providing direct overprinting of the first input by the second input. Since Schiller (1966) had shown spatial overlap or overprinting of the first input by the second input affected performance, in this study this variable was randomized over 2800 testing trials by selecting letters randomly, with the only constraint being that at least five or more points, of which the letters were composed, involved direct superposition. As indicated, all letters in Conditions A, B, and $C$ were chosen randomly, and all letters of the alphabet were employed with approximately equal frequency. Only one constraint was imposed, no letter was used more than once in any given pair. In Conditions $\mathrm{D}$ and $\mathrm{E}$ (i.e., those conditions involving word pairs), no words in any given pair had the same letter repeated. Further, the three- and five-letter words were chosen from the list of the first 1000 most frequently used words, as given in the Thorndike-Lorge (1944) word lists. One hundred three- and 100 five-letter words were chosen from this list at random and used in all of the pairings, with the constraint that no word pair used the same word twice.

\section{Procedure}

The stimulus pairs were displayed before the two Ss, using the two Fairchild CRT display consoles, in 20 separate testing sessions of 140 presentation pairs per session, for a total of 2800 presentation pairings per $\mathrm{S}$. Each of the 20 sessions, typically run 
Table 1

Per Cent Letters Correct for S R. H. for All Conditions of the Study

\begin{tabular}{|c|c|c|c|c|c|c|c|c|c|c|c|c|c|c|c|c|c|c|c|c|}
\hline \multirow[b]{4}{*}{ Off Times } & \multicolumn{20}{|c|}{ Conditions } \\
\hline & \multicolumn{4}{|c|}{$\begin{array}{c}A \\
\text { (2 letters) }\end{array}$} & \multirow{2}{*}{\multicolumn{4}{|c|}{$\frac{\mathrm{B}}{\text { (6 random letters) }} \frac{1}{\text { On Times }}$}} & \multirow{2}{*}{\multicolumn{4}{|c|}{$\begin{array}{c}\mathrm{C} \\
\frac{(10 \text { random letters })}{\text { On Times }} \\
\end{array}$}} & \multicolumn{4}{|c|}{\begin{tabular}{c}
\multicolumn{1}{c}{ D } \\
(2 3-letter words) \\
\end{tabular}} & \multicolumn{4}{|c|}{$\begin{array}{c}\mathrm{E} \\
(25 \text {-letter words) } \\
\end{array}$} \\
\hline & \multicolumn{4}{|c|}{ On Times } & & & & & & & & & \multicolumn{4}{|c|}{ On Times } & \multicolumn{4}{|c|}{ On Times } \\
\hline & 5 & 10 & 25 & 50 & 5 & 10 & 25 & 50 & 5 & 10 & 25 & 50 & 5 & 10 & 25 & 50 & 5 & 10 & 25 & 50 \\
\hline 1 & 15 & 35 & 38 & 80 & 10 & 12 & 22 & 48 & 12 & 7 & 18 & 25 & 11 & 18 & 46 & 89 & 18 & 19 & 21 & 85 \\
\hline 10 & 28 & 33 & 55 & 78 & 13 & 11 & 31 & 54 & 8 & 12 & 11 & 26 & 19 & 25 & 53 & 100 & 32 & 24 & 64 & 100 \\
\hline 25 & 50 & 65 & 63 & 78 & 28 & 22 & 47 & 69 & 12 & 12 & 25 & 33 & 38 & 62 & 80 & 95 & 38 & 63 & 89 & 94 \\
\hline 50 & 68 & 83 & 95 & 88 & 49 & 53 & 61 & 66 & 21 & 24 & 32 & 37 & 84 & 91 & 87 & 98 & 95 & 99 & 93 & 96 \\
\hline 75 & 90 & 88 & 90 & 98 & 66 & 51 & 73 & 73 & 26 & 30 & 33 & 32 & 100 & 98 & 100 & 99 & 98 & 99 & 97 & 95 \\
\hline 100 & 85 & 88 & 90 & 88 & 48 & 71 & 59 & 73 & 34 & 33 & 37 & 24 & 100 & 100 & 98 & 99 & 98 & 98 & 100 & 100 \\
\hline 125 & 93 & 95 & 93 & 95 & 72 & 72 & 64 & 75 & 32 & 36 & 32 & 46 & 95 & 98 & 100 & 99 & 97 & 100 & 98 & 100 \\
\hline
\end{tabular}

Note-On and Off times in msec.

once a day, consisted of 140 pairings, composed of the following timing combinations: on times of $5,10,25$, and 50 msec per input of each pair and off times of $1,5,10,25,50,75,100$, and 125 msec. This yields 28 different timing combinations, which when combined with a single instance of each of the five different conditions, i.e., A, B, C, D, and E, produces the 140 runs or trials (i.e., $5 \times 28=140$ ) for each testing session. Further, the 140 trials of any given session were ordered randomly. Since 20 testing sessions were involved, 20 data points were available for each of the 140 different testing combinations, producing the grand total of 2800 trials per $S$.

The Ss were given prepared answer forms on which they were to write down after each display presentation what they could recall, and were told "ready" approximately $1 / 2 \mathrm{sec}$ before each display was presented. Ample time was provided between each display, for each $S$ to write down what he could recall of that particular display pair, and illumination for this recall procedure was provided by two tensor lamps placed about $10 \mathrm{ft}$ behind each S's writing desk. These lamps were on during the entire testing session and in no way interfered with the quality of the image on the CRT display console.

\section{RESULTS}

The major results of the study are presented in Tables 1 and 2 . Table 1 gives for S R.H., for Conditions A, B, C, D, and E, the per cent of letters reported or detected correctly (i.e., the correct letter in the correct position and order) for all combinations of on and off times examined. As may be seen in Table 1, two trends in the data are clear. First, for all five conditions (i.e., A, B, C, D, and E), as on time increases from 5 to $50 \mathrm{msec}$, the per cent of letters detected correctly increases, and second, as off time increases from 1 to $125 \mathrm{msec}$, the per cent of letters detected correctly also increases. Further, it is quite clear that for Conditions A, D, and E, which involve either two letters or two words, the per cent values are remarkably similar, while for Conditions $B$ and $C$, which involve either three random letters overprinting three random

Table 2

Per Cent Letters Correct for Ss R.H. and P.K. as a Function of Total On+Off+On Display Times

\begin{tabular}{|c|c|c|c|c|c|c|c|c|c|c|c|}
\hline \multirow{2}{*}{$\begin{array}{c}\text { Display Times (msec) } \\
\text { On+Off }+ \text { On=Total Times }\end{array}$} & \multicolumn{2}{|c|}{ A } & \multicolumn{2}{|c|}{ B } & \multicolumn{2}{|c|}{$\mathrm{C}$} & \multicolumn{2}{|c|}{ D } & \multicolumn{2}{|c|}{$\mathrm{E}$} & \multirow{2}{*}{$\begin{array}{l}\text { ADE } \\
\text { Avg. }\end{array}$} \\
\hline & R.H & P.K. & R.H & P.K. & R.H & P.K. & R.H & P.K. & R.H. & P.K. & \\
\hline $5+1+5=11$ & 15 & 18 & 10 & 10 & 12 & 9 & 11 & 13 & 18 & 18 & 15.5 \\
\hline $5+10+5=20$ & 28 & 25 & 13 & 14 & 8 & 3 & 19 & 19 & 32 & 16 & 23.2 \\
\hline $10+1+10=21$ & 35 & 33 & 12 & 11 & 7 & 9 & 18 & 17 & 19 & 17 & 23.2 \\
\hline $10+10+10=30$ & 33 & 28 & 11 & 10 & 12 & 12 & 25 & 10 & 24 & 16 & 22.6 \\
\hline $5+25+5=35$ & 50 & 38 & 28 & 19 & 12 & 10 & 38 & 41 & 38 & 34 & 39.8 \\
\hline $10+25+10=45$ & 65 & 45 & 22 & 28 & 12 & 13 & 62 & 68 & 63 & 59 & 55.3 \\
\hline $25+1+25=51$ & 38 & 28 & 22 & 21 & 18 & 17 & 46 & 32 & 21 & 37 & 33.6 \\
\hline $25+10+25=60$ & 55 & 43 & 31 & 26 & 11 & 15 & 53 & 51 & 64 & 75 & 56.8 \\
\hline $5+50+5=60$ & 68 & 85 & 49 & 41 & 21 & 22 & 84 & 93 & 95 & 85 & 85.0 \\
\hline $10+50+10=70$ & 83 & 78 & 53 & 51 & 24 & 27 & 91 & 97 & 99 & 96 & 90.6 \\
\hline $25+25+25=75$ & 63 & 70 & 47 & 44 & 25 & 22 & 80 & 97 & 89 & 89 & 81.3 \\
\hline $5+75+5=85$ & 90 & 83 & 66 & 50 & 26 & 30 & 100 & 90 & 98 & 100 & 93.5 \\
\hline $10+75+10=95$ & 88 & 88 & 51 & 59 & 30 & 32 & 98 & 100 & 99 & 98 & 95.2 \\
\hline $25+50+25=100$ & 95 & 83 & 61 & 55 & 32 & 28 & 87 & 100 & 93 & 93 & 91.8 \\
\hline $50+1+50=101$ & 80 & 93 & 48 & 50 & 25 & 18 & 89 & 98 & 85 & 84 & 88.2 \\
\hline $50+10+50=110$ & 78 & 73 & 54 & 48 & 26 & 27 & 100 & 100 & 100 & 96 & 91.2 \\
\hline $5+100+5=110$ & 85 & 95 & 48 & 51 & 34 & 32 & 100 & 98 & 98 & 98 & 95.6 \\
\hline $10+100+10=120$ & 88 & 80 & 71 & 62 & 33 & 41 & 100 & 100 & 98 & 97 & 94,0 \\
\hline $50+25+50=125$ & 78 & 95 & 69 & 53 & 33 & 34 & 95 & 100 & 94 & 100 & 93.6 \\
\hline $25+75+25=125$ & 90 & 95 & 73 & 59 & 33 & 29 & 100 & 100 & 97 & 100 & 97.0 \\
\hline $5+125+5=135$ & 93 & 100 & 72 & 69 & 32 & 32 & 95 & 98 & 97 & 100 & 97.0 \\
\hline $10+125+10=145$ & 95 & 98 & 72 & 78 & 36 & 38 & 98 & 100 & 100 & 100 & 98.5 \\
\hline $50+50+50=150$ & 88 & 88 & 66 & 63 & 37 & 33 & 98 & 100 & 96 & 100 & 95.0 \\
\hline $25+100+25=150$ & 90 & 98 & 59 & 64 & 37 & 36 & 98 & 97 & 100 & 95 & 96.0 \\
\hline $50+75+50=175$ & 98 & 95 & 73 & 73 & 32 & 32 & 99 & 100 & 95 & 98 & 97.5 \\
\hline $25+125+25=175$ & 93 & 95 & 64 & 64 & 32 & 35 & 100 & 100 & 98 & 98 & 97.0 \\
\hline $50+100+50=200$ & 88 & 95 & 73 & 74 & 24 & 35 & 99 & 100 & 100 & 100 & 97.0 \\
\hline $50+125+50=225$ & 95 & 100 & 75 & 66 & 46 & 35 & 99 & 100 & 100 & 100 & 99.0 \\
\hline
\end{tabular}


letters or five random letters overprinting five random letters, respectively, the per cent values are much smaller. This result is quite understandable, since $S$ is now required to report not just 2 inputs, but either 6 or 10 separate inputs. It is important to note, however, that while the per cent values are lower for Conditions $B$ and $C$ than for Conditions $A, D$, and $E$, the per cent increases, associated with on and off time increases, continue to obtain, as seen in Conditions A, D, and E. The results obtained for S P.K. were almost identical with those obtained with S R.H.

Table 2 shows the results for both Ss, i.e., R.H. and P.K., organized in a somewhat different fashion than Table 1, which leads to another type of conclusion concerning the effects of on and off times on input processing. In Table 2 the 28 on and off time combinations have been ordered in terms of total time of 11 msec (i.e., 5 msec on +1 msec off +5 msec on) and a maximum total time of $225 \mathrm{msec}$ (i.e., $50 \mathrm{msec}$ on $+125 \mathrm{msec}$ off $+50 \mathrm{msec}$ on). The most striking result of this analysis would appear to be the generally linear and gradual increase, with one exception, in per cent correct detections up to approximately $51 \mathrm{msec}$, followed by a very large and what appears to be a discontinuous break in the per cent correct detections between $51 \mathrm{msec}$ and $60 \mathrm{msec}$. This break is most noticeable for Conditions $A, D$, and $E$ (whose average value is given in the last column of Table 2 ) and obtains for both Ss. Even Conditions B and C show perhaps similar, but very much less marked discontinuities in the data. Two further observations need to be made with respect to the data shown in Table 2. First, the abrupt increase found in per cent correct detections for a total time of $45 \mathrm{msec}$, with a drop back in per cent correct detections at $51 \mathrm{msec}$. This reversal, and drop back, for both $\mathrm{Ss}$ we believe is a direct consequence of the $1 \mathrm{msec}$ off time associated with this condition, while with the $45 \mathrm{msec}$ total time condition, the off time is $25 \mathrm{msec}$. Also, the marked differences in per cent correct detections for the two identical total times of $60 \mathrm{msec}$ is also a result, we believe, of the marked difference in off times (i.e., $10 \mathrm{msec}$ vs $50 \mathrm{msec}$ ). Second, apart from the drop in per cent correct detections for one of the 60 msec total time values, when the off time is only $10 \mathrm{msec}$, all total times from 60 msec on up for Conditions $A, D$, and E, for both $S$, are with few exceptions above $80 \%$ correct detections and most values are above $90 \%$ correct detections.

In addition to the analyses presented in Tables 1 and 2, a further analysis was made of the per cent correct detections for all conditions for the first and second inputs separately, for both Ss. This analysis showed clearly for both Ss that for Conditions B and $C$, per cent correct detections was always substantially higher for Input 2 than for Input 1. For example, for S R.H. the per cent correct detections averaged across all 28 timing combinations for Input 2 for Conditions $B$ and $C$ were $63 \%$ and $34 \%$, respectively, while for Input 1 the equivalent averages were only $36 \%$ and $15 \%$, respectively. For Conditions $A, D$, and $E$, Input 2 was only very slightly better than Input 1 and for a few timing combinations was very slightly poorer. For example, again for $\mathrm{S}$ R.H. the per cent correct detections averaged across all 28 timing combinations for Input 2 for Conditions A, D, and E were $77 \%$, $80 \%$, and $81 \%$, respectively, while for Input 1 the equivalent averages were $70 \%, 75 \%$, and $75 \%$, respectively. S P.K. gave essentially identical results as S R.H., for all five conditions. In all other respects, the trends of per cent correct detections as a function of the 28 different on-off time combinations were essentially identical with those trends shown in Tables 1 and 2 .

\section{DISCUSSION}

It is felt that the results of the present study suggest at least one very important implication for the SVE component of our visual information processing model. As discussed at some length in a previous paper (Mayzner, Tresselt, \& Helfer, 1967b), inputs enter the SVE component of the model approximately 100 to $130 \mathrm{msec}$ after their arrival at the visual receptor mechanisms and require another approximately $100 \mathrm{msec}$ to pass through the SVE component before retrieval from central storage is possible.

The results shown in Tables 1 and 2 indicate that the input processing in SVE associated with two overprinted sequential inputs is a function of both the on and off times associated with these inputs. More important,'perhaps, if the discontinuous break in the per cent correct detections when total processing time (i.e., on + off + on time) increases from $51 \mathrm{msec}$ to $60 \mathrm{msec}$. As may be seen in the last column of Table 2, which gives the average per cent correct detections for both Ss, for Conditions $A, D$, and $\mathrm{E}$, there is a jump from $33.6 \%$ correct detections to $85.0 \%$ correct detections, a jump of some $51.4 \%$ in a time span of only $9 \mathrm{msec}$ of total processing time. It is also important to note that two total processing time values of $60 \mathrm{msec}$ occur in Table 2, having associated with them $56.8 \%$ correct detections and $85.0 \%$ correct detections. Since one of these $60 \mathrm{msec}$ values is composed of 25 on +10 off +25 on, while the other $60 \mathrm{msec}$ value is composed of 5 on +50 off +5 on, it becomes reasonable to speculate that off time is more important than on time in producing the jump from $33.6 \%$ correct detections to $85.0 \%$ correct detections, when total processing time increases from 51 to $60 \mathrm{msec}$. This speculation seems reasonable, since for the lower value of $56.8 \%$ correct detections associated with a total processing time value of 60 msec, on time is $25 \mathrm{msec}$ (i.e., five times more than the on time of $5 \mathrm{msec}$ associated with the $85.0 \%$ value), while off time is $10 \mathrm{msec}$ (i.e., five times less than the off time of 50 msec associated with the $85.0 \%$ value). Thus, with total processing time held constant at $60 \mathrm{msec}$, increasing on time by a factor of five has much less effect than increasing off time also by a factor of five. This same type of relationship also obtains for the two equal total processing time values of $110 \mathrm{msec}$, but to a much lesser degree, since one is already almost at the asymptote of $100 \%$ correct detections.

Further, support for our contention that while both on and off times contribute to per cent correct detections as demonstrated in Table 1 , off time is the more critical factor, since Table 2 indicates higher correct detections (i.e., 55.3\%) for a total processing time value of $45 \mathrm{msec}$ than for a total processing time value of $51 \mathrm{msec}$ (i.e., $33.6 \%$ ). This reversal is, we believe, directly attributable to the $1 \mathrm{msec}$ off time associated with the $33.6 \%$ value, while the higher value of $55.3 \%$ is associated with an off time value of 25 msec.

The previous results and arguments suggest then that if two overprinted inputs are separated in time by about $50 \mathrm{msec}$ or more, as they pass through SVE, little if any interference will occur, and both inputs will be reported or detected correctly. On the other hand, if two overprinted inputs are separated in time by about $50 \mathrm{msec}$ or less, as they pass through SVE, interference will occur and will increase in a generally linear fashion as the time separation between the two inputs decreases. This value of 50 msec which emerges from the analysis of the results shown in Table 2 may well be related to the values of $50 \mathrm{msec}$ often cited as related to excitability cycles, cortical scanning, psychological moments, and the like (Harter, 1967). However, the results obtained under Conditions $\mathrm{B}$ and $\mathrm{C}$ of this study, while very mildly suggestive of a discontinuity between 51 and $60 \mathrm{msec}$, certainly could not be interpreted in the same way as the results for Conditions A, D, and E. Of course, it could be argued that Conditions $B$ and $C$ involve six or 10 separate inputs, not just two inputs as in Conditions $A, D$, and $E$, and therefore storage and retrieval factors would tend to confound any clear picture which might emerge supporting the concept of a psychological moment.

Still further evidence possibly counter to the moment concept may be found in some pilot data just collected, in which 5 Ss received either two or three five-letter words in an overprinting paradigm, and where each word was displayed for $10 \mathrm{msec}$ with $100 \mathrm{msec}$ between words for 10 trials and $600 \mathrm{msec}$ between words on another 10 trials. The results showed, if two words were displayed, essentially $100 \%$ correct detections for both the 100 and $600 \mathrm{msec}$ conditions, which is, of course, in complete agreement with the results of the present study. However, for the three-word string, while the $600 \mathrm{msec}$ condition continued to show essentially $100 \%$ correct detections for the three inputs, the $100 \mathrm{msec}$ condition dropped to about $50 \%$ correct detections for the three inputs. Thus, adding only one additional input, even 
with 100 msec separation between inputs, can produce very marked decrements in performance. This finding certainly suggests that a simple increase of just one input can markedly affect overall input processing and does not seem to fit easily into a "moment" value model of $50 \mathrm{msec}$ duration.

Thus, it would appear that if two inputs enter SVE separated by $50 \mathrm{msec}$ or more, little if any interference will occur, but if three inputs enter, separated by as much as $100 \mathrm{msec}$, either interference develops in SVE (which as our model now stands is ruled out since SVE processing time itself is estimated to be on the order of only $100 \mathrm{msec}$ ) or the interference found with three inputs occurs beyond the SVE component in the central storage, rehearsal, and retrieval components of the model. Further work is in progress in an attempt to better locate these sources of interference in input processing.

It would seem safe to conclude at this point that SVE processing will need to accommodate the $50 \mathrm{msec}$ interference value found in this study. Further, since we know from Schiller's (1966) work that stimulus intensity affects per cent correct detections, this parameter will also need to be incorporated into our model and research is currently being planned to examine intensity effects on input processing, while holding all other variables constant.

Finally, our findings just for Condition A (in which a single letter overprinted a single letter and which is the exact paradigm used by Schiller (1966) in his study of forward and backward masking) are in excellent agreement with Schiller's results. Specifically, Schiller found a very slight tendency for his first input $(90.6 \%$ for S R.M. and $91.6 \%$ for S S.G.) to be detected better than his second input $(82.8 \%$ for S R.M. and $85.2 \%$ for $\mathrm{S}$ S.G.), while we found a very slight reversal (i.e., input $1-70 \%$ for S R.H. and $73 \%$ for S P.K.: input $2-77 \%$ for S R.H. and $73.6 \%$ for S P.K.). Since Schiller employed a tachistoscope, while we employed a CRT display, the agreement between the two studies, for that condition where a direct comparison is possible, is very encouraging. and suggests no artifacts are present in cither study due to the particular display equipment employed.

\section{REFERENCES}

HARTER, M. R. Excitability cycles and cortical scanning: A review of two hypotheses of central intermittency in perception. Psychological Bulletin, $1967,68,47-58$.

MAYZNER, M. S. The research potential of a computer-based cathode-ray tube display system. Behavior Research Methods and Instrumentation, $1968,1,1,41-43$.

MAYZNER, M. S., TRESSELT, M. E., \& HELFER, M. S. A research strategy for studying certain effects of very fast sequential input rates on the visual system. Psychonomic Monograph Supplements, 1967a, 2, No. 5 (Whole No. 21), 73-81.

MAYZNER, M. S., TRESSELT, M. E., \& HELFER, M. S. A provisional model of visual information processing with sequential inputs. Psychonomic Monograph Supplements, 1967b, 2, No. 7 (Whole No. 23), 91-108.

SCHILLER, P. H. Forward and backward masking as a function of relative overlap and intensity of test and masking stimuli. Perception \& Psychophysics, 1966, 1, 161-163.

THORNDIKE, E. L., \& LORGE, I. The teacher's word book of 30,000 words. New York: Teachers College, Columbia University, Bureau of Publications, 1944.

\section{NOTES}

1. This research was supported by the Engineering Psychology Branch (Code 455) and the Personnel and Training Branch (Code 458) of the Office of Naval Research under ONR Contract No. N00014-67-A-0467-0001 and ONR Contract Authority No. NR 196-072.

2. Address: Department of Industrial Engineering and Operation Research, New York University, University Heights, Bronx, N. Y. 10453.

(Accepted for publication August 2, 1968.) 